\title{
As Carências no Cenário do Transporte Público nas Perspectivas dos Usuários na Cidade de Manaus
}

The Characters in the Public Transportation Scenario in the Perspectives of the Users in the City of Manaus

Las Fallas en el Escenario de Transporte Público en las Perspectivas de los Usuarios de la Ciudad de Manaus

Daniel Quintino de Jesus Silva ${ }^{1}$ Discente de Administração: UFAM/ AM

Marcelo Mendonça Alves ${ }^{1}$ Discente de Administração: UFAM/ AM

Paula Rezende Heck ${ }^{1}$ Discente de Administração: UFAM/ AM

Marcelo Alves da Silva ${ }^{1}$ Docente de Administração: UFAM/ AM prmarceloas@hotmail.com Universidade Federal do Amazonas, UFAM, Brasil $^{1}$ 


\title{
Resumo
}

Um dos maiores desafios da Administração Pública nas cidades tende a ser o gerenciamento do transporte. Sabidamente a cidade de Manaus cresceu, sem o planejamento urbano adequado. Neste ensaio abordaremos a temática, visando refletir sobre os principais problemas do serviço de transporte público, buscando analisar as razões que impedem a melhoria do sistema de transporte público da cidade de Manaus, a partir do olhar dos usuários. As políticas públicas de desenvolvimento e investimento que são realizadas na mobilidade urbana não estão cismáticas com o problema do transporte público. $\mathrm{O}$ artigo tem por finalidade analisar as carências do transporte público em Manaus, a partir de um questionário qualitativo e quantitativo realizado pelos acadêmicos de Administração juntamente aos usuários do transporte público para avaliar essa problematização. A metodologia utilizada neste ensaio foi a pesquisa bibliográfica, buscando identificar os fatores que os usuários consideram mais relevantes para um transporte público com maior qualidade. A pesquisa elencou como pontos críticos a serem melhorados: Espera do usuário do transporte público, ônibus velhos, excesso de lotação, falta de segurança, preços injustos, falta de manutenção dos veículos e, por fim, a falta de opções de modais. Assim, o estudo concluiu que parte dos usuários do transporte público coletivo na cidade de Manaus, está insatisfeita com as prestações de serviços no tecido social.

Palavras-chave: Políticas Públicas. Qualidade do Serviço. Satisfação dos Usuários. Transporte público.

\section{The Characters in the Public Transportation Scenario in the Perspectives of the Users in the City of Manaus}

\begin{abstract}
One of the biggest challenges of public administration in cities tends to be transportation management. The city of Manaus is known to have grown without proper urban planning. In this essay we will approach the theme, aiming to reflect on the main problems of public transport service, seeking to analyze the reasons that prevent the improvement of the public transport system of the city of Manaus, from the users' perspective. The public policies of development and investment that are carried out in urban mobility are not schismatic with the problem of public transport. The article aims to analyze the needs of public transport in Manaus, based on a qualitative and quantitative questionnaire conducted by management academics together with public transport users to evaluate this problem. The methodology used in this essay was bibliographic research, seeking to identify the factors that users consider most relevant for a better quality public transport. The survey listed as critical points to be improved: Waiting for the public transport user, old buses, overcrowding, lack of security, unfair prices, lack of maintenance of vehicles and, finally, the lack of modal options. Thus, the study concluded that part of the users of public transportation in the city of Manaus is dissatisfied with the provision of services in the social fabric.
\end{abstract}

Keywords: Public Policies. Service Quality. User Satisfaction. Public Transportation.

\section{Las Fallas en el Escenario de Transporte Público en las Perspectivas de los Usuarios de la Ciudad de Manaus}

\section{Resumen}

Uno de los mayores desafíos de la administración pública en las ciudades tiende a ser la gestión del transporte. Se sabe que la ciudad de Manaus ha crecido sin una planificación urbana adecuada. En este ensayo abordaremos el tema, con el objetivo de reflexionar sobre los principales problemas del servicio de transporte público, buscando analizar las razones que impiden la mejora del sistema de transporte público de la ciudad de Manaus, desde la perspectiva de los usuarios. Las políticas públicas de desarrollo e inversión que se llevan a cabo en la movilidad urbana no son cismáticas con el 
problema del transporte público. El artículo tiene como objetivo analizar las necesidades del transporte público en Manaus, en base a un cuestionario cualitativo y cuantitativo realizado por académicos de gestión junto con los usuarios del transporte público para evaluar este problema. La metodología utilizada en este ensayo fue la investigación bibliográfica, buscando identificar los factores que los usuarios consideran más relevantes para un transporte público de mejor calidad. La encuesta se enumeró como puntos críticos a mejorar: esperar al usuario del transporte público, autobuses viejos, hacinamiento, falta de seguridad, precios injustos, falta de mantenimiento de vehículos y, finalmente, la falta de opciones modales. Por lo tanto, el estudio concluyó que parte de los usuarios del transporte público en la ciudad de Manaus no está satisfecho con la prestación de servicios en el tejido social.

Palabras Clave: Políticas públicas. Calidad de servicio. Satisfacción del usuario. Transporte público. 


\section{INTRODUÇÃO}

Diversas capitais brasileiras apresentam graves impasses com a prestação do transporte público, e com a qualidade de vida, conforme recentes pesquisas realizadas pelo Instituto de Pesquisa Econômica Aplicada - IPEA (2017). O elevado número de veículos de transporte individual contribui para a baixa mobilidade no transporte público, para o aumento da poluição ambiental na cidade, e o elevado índice de acidentes de trânsito, potencializando o caos urbano, sendo assim, exigindo da prefeitura maior planejamento do trânsito e do transporte público.

O transporte público de passageiros na cidade de Manaus é uma das necessidades "básicas" sociais na contemporaneidade, pois o tecido social advém da demanda de deslocamentos do ponto $\mathrm{A}$ ao ponto $\mathrm{B}$, que precisam ser atendidas por sistemas de transportes estruturados $\mathrm{e}$ regulados de modo a cumprir com eficácia o direito da mobilidade e acessibilidade urbana. $\mathrm{O}$ fator chave em seu gerenciamento é saber onde estão e para onde vão os clientes, ou seja, traçar parâmetros de desempenhos logísticos de uma "entrega direta" ao invés de uma "entrega fracionada" que é o que ocorre atualmente. A gravidade da situação do fluxo urbana ressalta a relevância do transporte coletivo analisando a expansão da oferta e da utilização do modal rodoviário de transporte, a veracidade é que há uma grande precariedade na prestação de serviços e falta de segurança. A qualidade do fornecimento do serviço de transporte público é marcada como um vasto problema na assistência eficiente a sociedade, tendo em vista que a aplicação de investimento da autoridade pública e das concessões de mobilidade urbana é escassa diante do crescimento demográfico (Silveira, 2011).

O responsável vital pelo processo do transporte público urbano é a autoridade pública municipal, que é previsto de acordo com o inciso V da cláusula 30 da Constituição Federal prevê que: "Cabe ao município organizar e prestar, diretamente ou sob o regime de concessão ou permissão, os serviços públicos de interesse local, incluído o de transporte coletivo, que tem caráter essencial". Brinco (2012) relatou que, o maior marco da mobilidade urbana no Brasil sucedeu em 2012 com a emissão da Lei Federal 12.581, nomeada de Lei da Mobilidade Urbana, que tratados preceitos federais para a Mobilidade Urbana no país e define as situações de deslocamento das pessoas e cargas nos espaços urbanos. O tributo no setor de transporte púbico, como examina Ramos (2013), tem sido debatido por peritos das áreas de mobilidade urbana na cidade e no país. Atualmente, a mobilidade urbana é determinada como um problema ao Estado, de acordo com o aumento de automóveis circulando ativamente na cidade, ausência de vias urbanas estruturadas, falta de segurança, e ausência da logística dentro do transporte público.

O regulamento de Trânsito Brasileiro publicado em 1997 estabelece que o município deve estabelecer de forma eficaz, as condições técnicas, requisitos de segurança, higiene e conforto para os veículos destinados a este fim (Bubicz \& Sellitto, 2009). No ano de2013, ocorreram pela nação brasileira e principalmente em Manaus movimentos protestantes voltados à má qualidade dos serviços de transporte público prestados, como apresenta (Pena, 2016), as reivindicações se voltaram para o núcleo do aumento no preço das passagens, qualidade do serviço prestado, ônibus com superlotação, veículos em más condições de uso e longos tempos de espera nos pontos de ônibus.

Nota-se a grande relevância do estudo e também do relatório a respeito do transporte público, uma vez que estão relacionados com a qualidade de vida dos manauaras, tendo como objetivo uma explanação em nível de recorte a respeito das maiores dificuldades na persecução no 
transporte público na visão dos usuários, a contar com o auxílio de ferramentas de processamento de dados e de simulação de transportes, identificar os atributos qualitativos e os fatores que geram impactos na satisfação com a qualidade dos serviços de transporte público urbano de ônibus. Em Manaus, o uso do transporte individual.

O transporte público deve ser priorizado, segundo o relatório geral realizado pelo Instituto de Energia e Meio Ambiente (IEMA, 2016),denotando uma grande discrepância entre o desempenho de automóveis, motocicletas e ônibus entre os anos de 1990 e2016. As políticas públicas sociais são variadas programas, e atividades criados pelo próprio Estado influenciando diretamente ou indiretamente, com uma participação difusa entre entes públicos ou privados, com objetivo de assegurar o direito da cidadania, correspondendo aos direitos constitucionais, no transporte tratam-se de um dispositivo de política redistributiva, em que se poderia taxar o transporte individual motorizado para subsidiar o transporte coletivo e não motorizado, visando à renda como forma de financiamento em prestação de serviços e equipamentos no ato do recurso, em vista que as camadas altas do tecido social são os maiores responsáveis pelo o financiamento dos beneficiários (no caso, pessoas com renda menores). As políticas públicas redistributivas são vistas como direitos sociais, um patamar de discordância maior devido ao jogo zero que essa política tem como característica.

O automóvel é o meio de transporte mais utilizado no dia a dia, seguido da motocicleta e por último o uso do ônibus, sendo o veículo utilizado para o transporte coletivo de passageiros. Os especialistas em trânsito de Manaus apontam que a redução de passageiros no exercício em2018, é o reflexo de problemas antigos, como a fragilidade, a falta de segurança e o preço. Por isso, as pessoas estão rastreando alternativa no transporte por aplicativo. Os usuários apontam as dificuldades em usufruir do transporte público em Manaus, alegando que os ônibus são precários e não cumprem com os horários programados, potencializando os fatores negativos. A pesquisa verificou que os usuários de aplicativos aumentaram, dependendo das conjunções, é viável ir adiante com o transporte por aplicativo, do que de ônibus, os usuários do transporte coletivo alegaram.

Este ensaio está estruturado em resumo, palavras-chaves, introdução, revisão literária, metodologia e pesquisa, discussão, análise dos resultados, considerações finais, e bibliografias.

\section{REFERÊNCIAL TEÓRICO}

Serão apresentaras as definições de políticas públicas que foram elaboradas por diversos estudiosos e como elas são desenvolvidas para serem aplicadas na sociedade. Em seguida, o conceito de transporte público e como funciona o seu serviço sendo uma política pública. Também serão tratadas as questões de qualidade e satisfação dos seus usuários sobre o serviço prestado no transporte público. E por fim, o atual cenário do serviço de transporte público na cidade de Manaus.

\subsection{Definições de Políticas Públicas}

Não existe uma definição concreta sobre a interpretação do conceito de política pública. No decorrer das décadas, o conceito de política pública foi obtendo novos significados. Vários especialistas contribuíram para a construção da definição do que seja a política pública, introduzindo suas visões e análises em respectivas épocas. 
Segundo Mead (1995 apud Souza, 2002), política pública é um campo dentro do estudo da política geral que visa analisar o governo por meio de grandes problemas de ordem pública. Lynn (1980 apud Souza, 2002), define como um conjunto de ações e decisões estabelecidas pelo governo que ocasiona efeitos específicos. Para Peters (1986 apud Souza, 2002), política pública é a totalidade das ações dos governantes, que atuam diretamente ou por meio de delegação, e que influenciam a vida do tecido social. Para Dye (1984 apud Souza, 2002), política pública como sendo a ação ou não ação do governo. Destarte, política pública é compreendida como um conjunto de ações, decisões e programas desenvolvidos pelo governo (nacional, estadual ou municipal) para as soluções (ou não) dos problemas de interesses públicos buscando o bem-estar da sociedade.

Segundo David Easton (1984 apud Agum, Riscado, \&Menezes, 2015), em meio à década de 1960, o resultado das políticas públicas é influenciado diretamente por grupos de interesse, sendo a política pública um sistema com várias interfaces. Agum, Riscado, e Menezes (2015) relatam que as políticas públicas afetam todos os individuas, de todos os níveis de escolaridade, independente dos grupos nos quais estejam inseridos na sociedade. O governo tem a responsabilidade de promover o bem-estar dos cidadãos por meio das ações das políticas públicas nas resoluções dos problemas da sociedade nas áreas da educação, saúde, transporte, segurança, moradia, infraestrutura, emprego e meio ambiente. As ações dos governantes com as elaborações das políticas públicas visam à satisfação das demandas e a diminuição dos problemas públicos. Os governos deveriam escolher (suas prioridades) com base na demanda e perspectivas dos cidadãos. Sendo assim, o governo é responsável por desenvolver a qualidade de vida da sociedade.

\subsection{Desenvolvimentos de Políticas Públicas}

Na abordagem de Souza (2002) há vários debates sobre os papéis dos governos nas implementações e execuções de políticas públicas, em conjunto com outros segmentos, que não são os governos e, se envolvem na elaboração das políticas públicas. As demandas apresentadas pela população são direcionadas aos governantes por meio da Sociedade Civil Organizada (SCO), que é o conjunto de organizações e instituições cívicas voluntárias que se constitui por grupos organizados como sindicatos, entidade de representação empresarial, associação de moradores, associações patronais e Organizações Não Governamentais (ONGs) em geral.

Agum, Riscado, e Menezes (2015, p.23) apresentam a proposta de entendimento da Política Pública organizada como um ciclo, chamada por Lindblon de Ciclo da Política Pública (Policy Cycle), se traduz na dinâmica do processo feita de maneira temporal. O clico de processo da elaboração das políticas públicas é construído por etapas que são organizadas de maneira especificas, apresentadas de forma em que possam ser entendidas e interpretadas. As elaborações das políticas públicas são constituídas por seis etapas: identificação do problema, formação da agenda, formulação de alternativas, tomada de decisão, execução da política pública e avaliação (Agum, Riscado, \& Menezes, 2015). Aprendendo e analisando essas etapas pode-se entender como são realizadas e executadas as políticas públicas pelos os governos de uma sociedade.

\subsection{Políticas de Transporte Público em Manaus}


O transporte público, de acordo com a Lei Federal $\mathrm{n}^{\circ}$ 12.587, de 2012, é definido como serviço público de transporte de passageiros, disponível a todos os cidadãos, mediante pagamento individualizado, com itinerários e preços, estabelecidos pelo poder público; ou como individual definido como serviço remunerado de transporte de passageiros aberto ao público, por intermédio de veículos de aluguel, para a realização de viagens individualizadas (Strehl, Moyano, \& Angnes, 2019).

O serviço de transporte coletivo é uma política pública redistributiva. Esse tipo de política pública visa redistribuir a renda em forma de financiamento em serviços e equipamentos e na forma de recursos. Tirando de grupos mais altos da sociedade que são as responsáveis por financiar os grupos com rendas menores, os chamados beneficiários. Essas políticas atingem uma grande parte da população e são vistas como direitos sociais (Rua \& Romanini, 2013).

Durante o processo de urbanização, a cidade de Manaus passou por várias transformações no serviço do transporte público. Com a criação do Transporte Amazon, uma empresa de iniciativa pública e privada, se iniciou a utilização do serviço de transporte coletivo em Manaus durante os anos de 1957 a 1980. Na década de 80, após a implantação da Zona Franca, é criado o primeiro órgão de gestão do transporte urbano de Manaus, a Empresa Municipal de Transportes Urbanos (EMTU) (Almeida et al., 2017).

No ano de 1997, o EMTU se tornou o Instituto Municipal de Transportes Urbanos (IMTU). Quase 30 anos depois, sendo substituído pelo Instituto Municipal de Trânsito e Transportes (IMTT). Em 2010, passa a ser utilizado o nome em vigor, Superintendência Municipal de Transportes Urbanos (SMTU), fundado juntamente com o Instituto Municipal de Engenharia e Fiscalização do Trânsito (Manaustrans). Atualmente o SMTU realiza fiscalizações no transporte público da cidade, com a missão de programar ações estratégicas de planejamento, operação e fiscalização, que envolvem os serviços essenciais de transporte público, priorizando a segurança dos usuários e a prestação de serviços com qualidade e eficiência na capital amazonense (Almeida et al., 2017).

O transporte coletivo pode ser considerado como um meio de transporte utilizado por muitas pessoas simultaneamente, tornando o custo unitário baixo e de acesso público, sendo o serviço prestado por uma empresa ou prefeitura. Não existe flexibilidade de uso, pois os itinerários e os horários são fixos, e as viagens não são de porta a porta, havendo necessidade de completá-las com percursos a pé ou utilizando outros modos. Uma das formas mais comuns de transporte coletivo é o de ônibus (Strehl, Moyano, \& Angnes, 2019).

\subsection{Qualidade do Transporte Público}

O setor de transporte público de passageiros por ônibus em Manaus exerce papel fundamental de integração do transporte urbano, afetando diretamente a produção das demais atividades econômicas, em função da sua própria qualidade e produtividade. Assim, a qualidade do serviço prestado deve ser atestada, pois existe uma ligação essencial entre o transporte coletivo urbano e o bem-estar de seus usuários.

De acordo com Araújo et al. (2011), a importância do transporte coletivo em uma cidade, influência a qualidade de vida dos cidadãos que o utilizam. O serviço de transporte coletivo utilizado pela população para fazer seu descolamento de sua moradia a respectivos locais na cidade, melhorando a sua mobilidade e acessibilidade. Afetando também o funcionamento do 
setor privado produtivo e das demais funções públicas (Neto, 2004 apud Araujo, Jesus, \& Lima, 2011). As perspectivas dos usuários de transporte coletivo são importantes para determinar as melhores medidas políticas no referido transporte. A decisão pela escolha se motiva pela percepção da qualidade do serviço prestado.

Segundo Guirão, García-Pastor, e López-Lambas (2016 apud Strehl, Moyano, \&Angnes, 2019), o nível de qualidade desejado pelos passageiros e cidadãos ofertados por prestadores de serviços é determinado por fatores externos e pressões, qualidade de espera, limitações orçamentárias e desempenho dos operadores. Identificar a percepção dos usuários tem impactos significativos na melhoria dos serviços de transporte público, fazendo os responsáveis pela prestação do serviço identificar melhorias para fornecer um transporte com mais eficiência e satisfação para seus usuários.

O sistema de transporte coletivo tem uma proporção grande de demanda realizada pela sociedade por apresentar uma flexibilidade para a conexão de pontos de início e os pontos de destinos, custos de implementações baixos e oferta adaptável a incrementos na demanda (até o limite da densidade de tráfego) (Barat \& Batista, 1973 apud Araujo, Jesus, \& Lima, 2011). Mas, com todos os problemas que o transporte coletivo de Manaus apresenta, sendo um deles a demora dos coletivos nas paradas como um dos problemas mais recorrentes, muitos de seus usuários passaram a utilizar outros meios de transporte para se locomover na cidade. Segundo informações do Sindicato das Empresas de Transporte de Passageiros do Estado do Amazonas (Sinetran). O sistema convencional de transporte coletivo de Manaus terminou o ano de 2018 com o saldo negativo no que diz respeito ao número de usuários pagantes. De janeiro a dezembro, 200 milhões de passagens foram registradas, uma queda de 19 milhões em relação a 2017. Essa redução é reflexa de problemas antigos como precariedade dos veículos, falta de segurança, preço abusivo da tarifa e a falta de investimentos públicos e privados em todo o sistema de transporte (Mota, 2019).

Na pesquisa realizada por Terra e Duarte (2014) eles destacam elementos que afetam diretamente a qualidade no transporte público coletivo.

- Acessibilidade é a distância percorrida pelo usuário para iniciar e finalizar a viagem por transporte público por meios edificados e espaços públicos seguros, saudáveis, adequados e agradáveis para que sejam utilizados por todas as pessoas, obtendo a comodidade no percurso.

- Frequência de atendimento é definida com o intervalo de tempo entre as passagens sucessivas de ônibus da mesma linha pelos pontos de parada, definido como headway na engenharia de tráfego, é mais sensível aos passageiros que desconhecem o horário e estão esperando no ponto de ônibus.

- Lotação é acentuada como a "quantidade de passageiros no interior dos coletivos", sendo alcançada a carga máxima de passageiro no interior dos ônibus.

- Confiabilidade, definida como grau de certeza que os usuários possuem sobre a parada de origem dos ônibus até a chegar ao seu destino final, juntando isso à pontualidade, conceituada como a regularidade dos horários das linhas.

- Segurança está relacionada à frequência de acidentes e assaltos corridos nos percursos e nos terminais de paradas dos veículos coletivos.

- Sistema de informação e apresentação de elementos que facilitam o acesso e a disponibilização quanto aos horários dos veículos, itinerários e se tem acesso aos deficientes físicos. 
Todos esses elementos devem ser analisados durante o planejamento de uma política de transporte coletivo de qualidade na sociedade, eles afetam toda sua estrutura desde sua iniciação até sua execução. Esses elementos são essenciais para a política de transporte público, se eles não forem aplicados de forma correta podem trazer problemas em todo o desenvolvimento da política de transporte público (Ferraz \& Torres, 2004 apud Terra \&Duarte, 2014). Quando esses fatores são aplicados de forma planejada e organizada, obtendo os recursos e atenção necessária dos governantes que a desenvolve e programam, todos os usuários desse transporte coletivo têm suas necessidades de locomoção supridas e sua satisfação alcançada.

\subsection{Satisfação do Transporte Público}

Pode ser entendida como satisfação do cliente a avaliação das expectativas e experiências obtidas do cliente pela utilização de um produto ou serviço. Quando o desempenho do produto ou serviços alcança a satisfação do cliente ele tende a volta a utiliza-los (Shanet al., 2014 apud Strehl, Moyano, \&Angnes, 2019). A satisfação do cliente após a experiência com os produtos ofertados é um dos principais diferencias competitivos, sendo de fundamental importância para uma organização. A satisfação do consumidor após a compra de determinado produto ou serviço depende do desempenho da oferta em relação com suas expectativas. Satisfação do cliente é ou deveria ser uma das principais preocupações de qualquer empresa. Afinal de contas, um cliente satisfeito é a melhor propaganda de uma marca (Kotler, 2000 apud Portaluppi, Heinzmann, Tagliapietra, \& Borilli, 2006).

As diversas manifestações sobre o aumento da tarifa do transporte coletivo que ocorreram em todo o Brasil durante os anos de 2010 e 2011vêm apontando a insatisfação dos usuários do transporte público no país. Em junho de 2013, ocorreram umas das primeiras manifestações para criticar o aumento nas tarifas de ônibus em dezenas de cidades. Em Manaus, o protesto teve acontecimento nas ruas do bairro Cidade Novo, muito usuários do transporte protestaram pelo aumento da tarifa de ônibus na capital. O Sindicato das Empresas de Transporte de Passageiros de Manaus (Sinetram) havia divulgado que o aumento da tarifa do transporte coletivo convencional deveria passar de $\mathrm{R} \$ 2,75$ para $\mathrm{R} \$ 3,50$, o que causaria um crescimento de $27,3 \%$ sobre o valor estabelecido. Com a crescente do movimento e novas reivindicações ganhando as ruas, os governos municipais e recuaram reduções nos preços (Souza, 2013).

Segundo o portal de notícias G1 Amazonas (2015) em janeiro, as manifestações se iniciaram na cidade de Manaus contra o aumento da tarifa do transporte coletivo. A manifestação teve início no Largo São Sebastião e prosseguiu nas ruas do Centro de Manaus até à Praça Dom Pedro II, que se encontrava interditada pela Guarda Municipal e por policiais militares da $24^{\mathrm{a}}$ Companhia Interativa. Muitos dos protestantes definiram o aumento do preço da passagem como "absurdo". Declararam que as condições dos ônibus são precárias e as paradas e ônibus estão lotados e muitas pessoas precisam pegar mais de um ônibus todos os dias e não tinham condições de pagar o valor estabelecido de $\mathrm{R} \$ 3,00$. O resultado da manifestação não foi esperando e o aumento da tarifa permaneceu, e em anos seguintes houve o aumento da passagem de $\mathrm{R} \$ 3,00$ para $\mathrm{R} \$ 3,80$. Os protestos vêm influenciando transformações políticas e alcançado objetivos, com isso, a agenda nacional de discussão desses temas também foi acelerada.

\subsection{O Cenário Atual na Cidade de Manaus}


Usuários do transporte coletivo na cidade de Manaus acreditam estarem sendo atendidos por carros sucateados, muitos reformados (maquiados), e que constantemente quebram. Um dado explícito que comprova o sofrimento dos usuários no dia a dia, é o grande número de panes mecânicas nos veículos que circulam nas ruas de Manaus. Somente no mês de março de 2019 foram detectadas 436 através de indicadores de desempenho, considerando que a frota é composta por 1.356 ônibus, podemos exemplificar como $30 \%$ de carros retirados das ruas devidos problemas mecânicos. Diversos manauaras pagam muito caro para enfrentar total desconforto, constrangimento, e insegurança como no ano vigente de 2018 onde a SSP informou que houve 2.397 assaltos a ônibus, sendo em média sete assaltos por dia, totalizando em um prejuízo em $\mathrm{R} \$ 554.998$ mil reais. A SMTU divulgou que só a empresa Açaí que atende a Zona Norte ao Centro responde por mais de $28 \%$ de panes mecânicas, seguida pela Global Green que atende a Zona Leste com $15 \%$ de panes, resultando que as suas empresas que transportam usuários das duas Zonas mais populosas de Manaus são as que circulam com os ônibus em piores condições.

O Sinetram salienta que são mais de 30 anos com os mesmos problemas na capital, onde atuam as mesmas empresas e empresários com a mesma cultura impregnada no sistema rodoviário, e o mesmo relata que o contrato com o Município não é cumprido pela as empresas, e que a prefeitura não fiscaliza, não intervém no sistema. A Lei Orgânica do Município, diz que a vida útil de todos os ônibus é de 10 anos, antigamente eram de apenas de 07 anos, após esse limite, deveriam ser substituídos por ônibus novos e modernos, porém, parte significativa já ultrapassou o limite.

Segundo os vereadores, a queda de usuários provocou precariedade no transporte público. O Sinetram alegou que o modal apresentou uma queda no faturamento desde 2016 na ordem de $25 \%$, reflexo da queda de passageiros, 1.300 coletivos circulavam em Manaus, distribuídos em 230 linhas de ônibus. Segundo o Sinetram, oito empresas operam neste modal com a média de 500 mil passageiros por dia. Os dados da Superintendência Municipal de Transportes Urbanos (SMTU), avaliam cerca de 1.356 ônibus que circulam na capital, sendo 178 articulados. São aproximadamente 2,9 mil duplas de cobrador e motorista trabalhando nos coletivos.

O supercrescimento do tecido social em Manaus resulta em frequentes congestionamentos e falta a de espaço em vias urbanas. Diariamente, vários veículos circulam por vias públicas na cidade, gerando transtornos que podem ser solucionados em parte com a utilização do transporte público, assim reduzindo o tráfego de veículos individuais em vias urbanas, diminuindo o congestionamento e a poluição ambiental em Manaus. Em pesquisas realizadas no ano de 2003, os entrevistados relataram grande satisfação em utilizar o transporte coletivo visando reduzir o número de carros individuais nas vias, com o intuito de reduzir os congestionamentos. Porém, só haverá uma migração funcional para o transporte público coletivo caso a própria população obtiver uma boa imagem dele e notar benefícios superiores aos custos incorridos, ao identificar os atributos qualitativos e fatores geradores de impactos na satisfação com a qualidade dos serviços de transporte público urbano de ônibus.

\section{METODOLOGIA}

Nesta pesquisa utilizamos a revisão de literatura, buscando identificar quais os fatores que os usuários consideram mais relevantes para que o serviço de transporte público tenha mais qualidade, para alcançarmos esse objetivo, nos baseamos em pesquisa bibliográfica, 
buscando identificar autores que realizaram pesquisas com essa temática, na etapa seguinte, realizamos leitura do material pesquisado com a finalidade de catalogarmos suas contribuições para o tema.

Por fim, construímos o texto final, identificando os critérios assinalados pelos usuários nas pesquisas. A aplicação do questionário demonstrou satisfatória nesse sentido. O método da pesquisa é fundamentado por aplicação do questionário criado e enviado pelas redes sociais aos usuários de transporte público para serem respondidos, sendo analisando estatisticamente.

De acordo com Günther (2006) é preciso, portanto, que aquele que busca a construção do conhecimento, por meio da pesquisa, utilize formas complementares, e não isoladas, de utilização da pesquisa quantitativa e qualitativa, sem se prender a um ou outro método, adequando-os para solução do seu problema de pesquisa. Com efeito, a partir dessa visão, percebe-se que as duas abordagens, qualitativa e quantitativa, vistas até certo tempo como antagônicas, podem apresentar um resultado mais considerável e significativo, se utilizadas na pesquisa de um mesmo problema.

Para a coleta de dados da pesquisa foi utilizado um questionário fechado composto de (dez) perguntas de múltipla escolha específicas para medir a qualidade da satisfação dos usuários com o serviço oferecido pelo transporte público, ou seja, a pesquisa é de caráter qualitativo e quantitativo. Os dados foram obtidos por meio de aplicativo Survey Monkey, com 500 pessoas que avaliaram o serviço de transporte público da cidade de Manaus.

A coleta foi realizada no dia 10 ao dia 27 de maio de 2019 e executada pelos discentes de Administração que compõem o grupo. Os dados foram organizados e sistematizados em planilha do Excel 2013 e foram apresentados por meio de indicadores de qualidade através de gráficos que avaliaram o serviço oferecido. Os dados demonstraram fatores como: tempo de viagem, segurança, pontualidade do serviço, infraestrutura dos terminais de integração, comunicação e fiscalização, condições do meio de transporte, custo da passagem pelo serviço oferecido, e outros, são aspectos avaliados como essências pelos usuários.

\section{ANÁLISES DOS RESULTADOS}

Conforme Las Casas (2008), o serviço de transporte público para ser entendido em seus aspectos é necessário compreender como os clientes percebem os mesmos. Há uma fonte de estímulos físicos para a percepção, além de fatores como necessidades, estado de ânimo, entre outros. Na prestação do serviço é preciso compreender que o usuário é o único que vê a execução do serviço como um todo, e por isso se torna elemento fundamental e a razão da prestação do mesmo. 
Você utiliza frequentemente o transporte público?

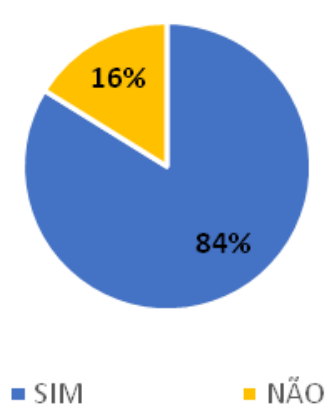

Figura 1. Utilização do transporte.

Fonte: Elaborado pelos autores.

Diversos indivíduos, de acordo com a Figura 1, ao serem indagados a respeito da frequência utilizada do transporte público, $84 \%$ alegaram que utilizam com frequência, pois não possuem condições suficientes para aderir e manter ao transporte individual, e $16 \%$ afirmaram que não utilizam o transporte público, pois aderiram ao meio de transporte individual devido à falta de qualidade na prestação do serviço ao tecido social. Porém, informaram que utilizariam o transporte público com satisfação caso o mesmo fosse de qualidade e eficiência, pois iria minimizar os transtornos de congestionamentos, constituiria a forma sustentável de substituir o automóvel, reduziria a probabilidade de acidentes no trânsito, seria um meio de transporte mais econômico que o privado, facilitaria a mobilidade do trânsito na cidade.

\section{Quantos veículos no transporte público você utiliza por dia?}

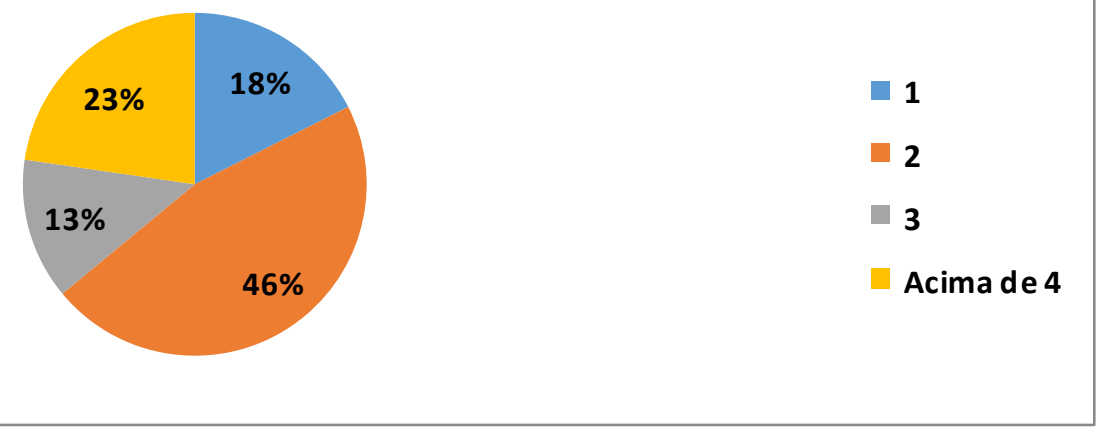

Figura 2. Quantidade de veículos utilizados no transporte público por dia.

Fonte: Elaborado pelos autores.

Na questão abordada de veículos usados VS dia, é notório que $46 \%$ da pesquisa predominante utilizamos somente dois veículos, que são consideravelmente normais, pois utilizam um para ir do seu ponto inicial ao seu destino, e outro para retornar ao seu ponto inicial, e que $23 \%$ utilizam mais de quatro veículos, tendo dificuldades em sua locomoção e acessibilidade, devido a política de logística fracionada que a cidade adota, gerando estresse no usuário. 


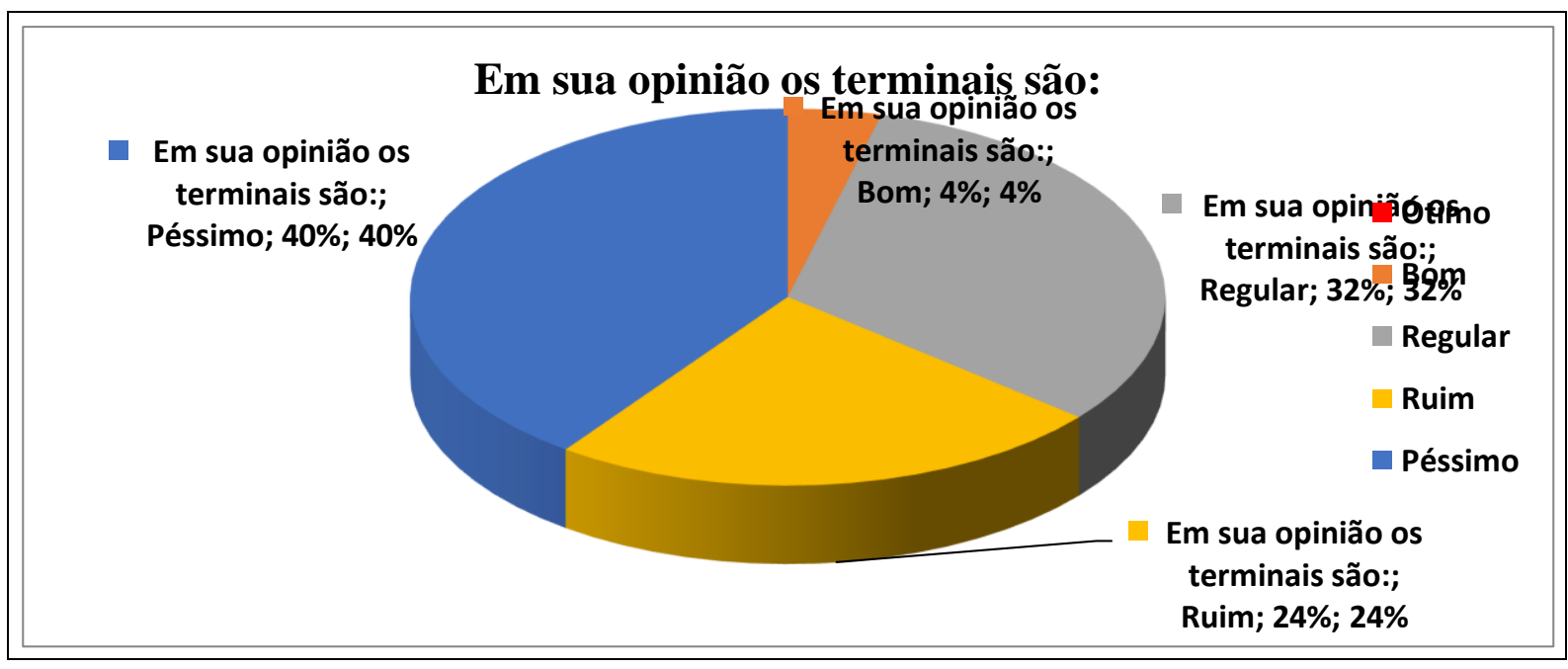

Figura 3. Qualidade dos terminais de ônibus da cidade de Manaus.

Fonte: Elaborado pelos autores.

Os dados reafirmam a realidade que é conhecida na cidade, onde os usuários sofrem com a infraestrutura nos terminais sob a responsabilidade da prefeitura, onde $40 \%$ dos usuários (Figura 3) alegam que os terminais não têm banheiros adequados, sem portas, sem cobertura, os terminais em si são bastante sujos, e não tem segurança alguma, e muito menos fiscalização. Oferecendo um serviço sem qualidade para esses usuários que o utilizam nas suas viagens.

\section{Considerando a qualidade do transporte público, o preço da passagem é:}

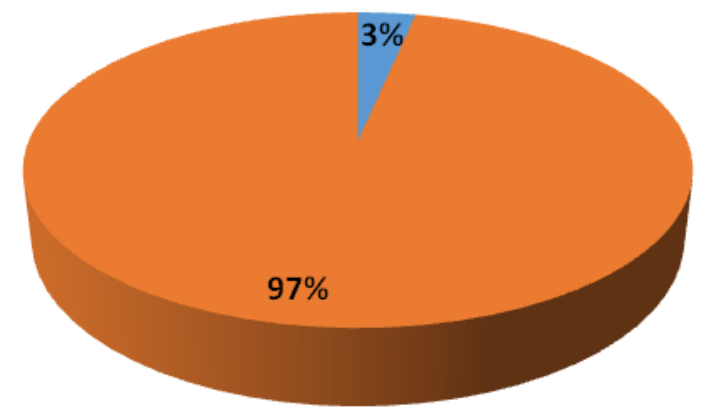

Figura 4. Preço da passagem de ônibus quanto à qualidade do serviço que é oferecido. Fonte: Elaborado pelos autores (2019).

Segundo a população, 97\% dos usuários (Figura 4) alegam que o preço de $\mathrm{R} \$ 3,80$ para a passagem em Manaus é totalmente injusta, devido à falta de infraestrutura, qualidade, eficiência, eficácia, segurança, e conforto na prestação de serviços de transporte público pelas as empresas/prefeitura, ocasionando nos últimos anos diversas paralisações realizada por usuários, e greves por parte dos rodoviários, questionando as condições de trabalho. 


\section{Existe ônibus suficiente para atender a demanda?}

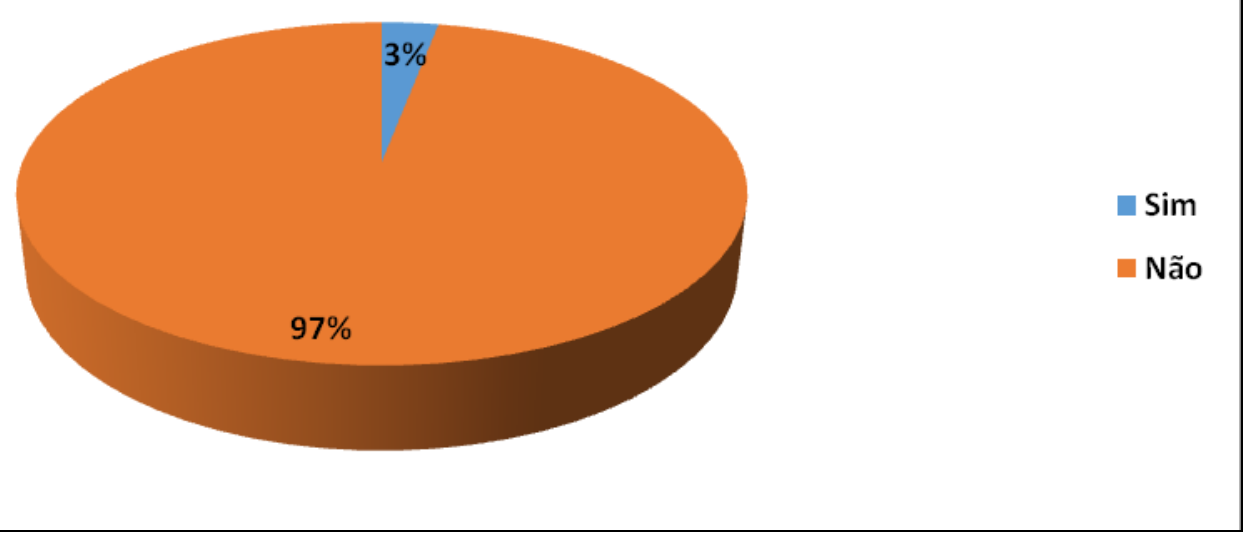

Figura 5. Atendimento da demanda.

Fonte: Elaborado pelos autores (2019).

Na pesquisa realizada, a população aponta que não existe ônibus suficiente para atender a demanda, gerando assim asuperlotação dos veículos, onde muitas vezes os veículos passam diretos das paradas, pois já não há mais espaço para que entrem novos usuários, por esse motivo há desconforto nos coletivos e insatisfação dos usuários pelo serviço prestado, atualmente circulam cerca de 1.356 veículos para atender uma demanda de 2,145 milhões pessoa em Manaus.

\section{Quanto tempo em média você aguarda o ônibus nas paradas/terminais?}

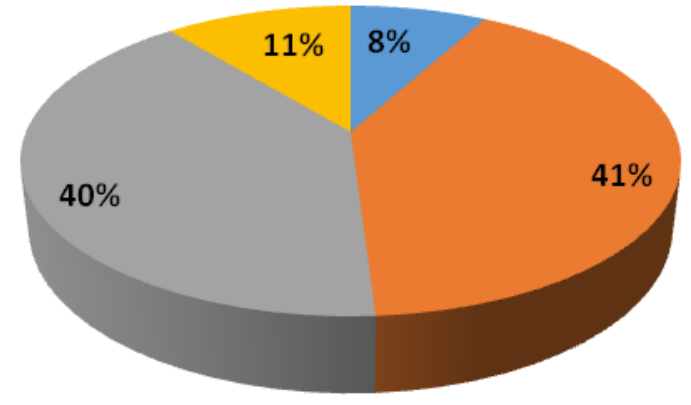

$5 \mathrm{~min} / 10 \mathrm{~min}$

20min/30min

$40 \mathrm{~min} / 50 \mathrm{~min}$

Acima de 1 hora

Figura 6. Tempo média de espera.

Fonte: Elaborado pelos autores.

Observa-se que $40 \%$ dos usuários aguardam de 40 a 50 minutos pelos ônibus nas paradas ou terminais de integração, enquanto que $11 \%$ esperam acima de 1 hora pelo seu coletivo (Figura 6). Essa situação na demora do coletivo gera mais insatisfação e ocasiona mais ônibus lotados, deve-se por meio de GPS, controlar o percurso dos coletivos e reduzir essa espera ou então verificar quais linhas precisam de um reforço na frota para diminuir esse tempo de espera nas paradas e terminais de integração. 


\section{O estado de conservação dos ônibus é:}

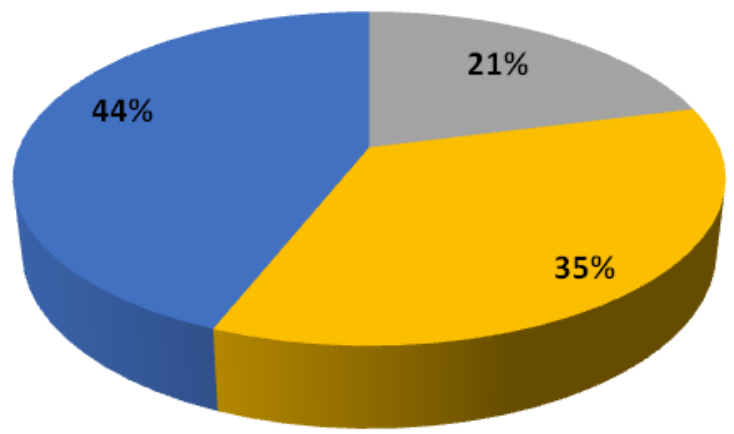

Figura 7. Conservação de ônibus.

Fonte: Elaborado pelos autores.

O estado de conservação dos ônibus (Figura 7) foi apontado como um dos maiores problemas do serviço de transporte público da cidade de Manaus, nenhuma pessoa avaliou como ótimo ou bom; um percentual de $21 \%$ avaliou como regular; $35 \%$ apontaram que é ruim a conservação dos coletivos, e; a maioria $44 \%$ disse que é péssimo o estado de conservação dos ônibus em nossa cidade, o que ocasiona uma grande insatisfação dos usuários do transporte público. Ônibus velhos, que quebram antes de chegar a seu destino, gerando uma ineficiência do serviço que hoje é oferecido a população.

\section{$O$ atendimento ao respeito às paradas e número de fiscais é:}

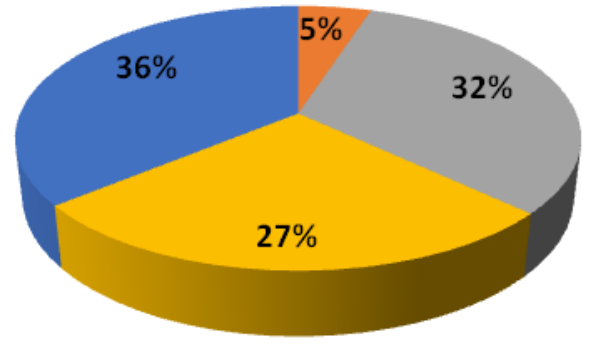

$$
\begin{aligned}
& \text { Ótimo } \\
& \text { Bom } \\
& \text { Regular } \\
& \text { Ruim } \\
& \text { Péssimo }
\end{aligned}
$$

Figura 8. Respeito em parar nas paradas de ônibus e quantidade de número de fiscais. Fonte: Elaborado pelos autores.

Percebe-se que falta respeito por parte dos motoristas em parar nas paradas de ônibus (Figura 8), pois somente $5 \%$ avaliaram como bom, o restante $32 \%$ avaliam como regular, $27 \%$ como ruim e a maioria $36 \%$ avaliam como péssimo o respeito em atender os usuários nas paradas de ônibus e também o número insuficiente de fiscais que possam verificar essa situação. Essa situação só reflete as perspectivas esperadas pelo o usuário, que nãosão alcançadas pelo o serviço prestado. 


\section{A identificação dos itinerários nos veículos, e o acesso à informações sobre mudança de rotas ou horários:}
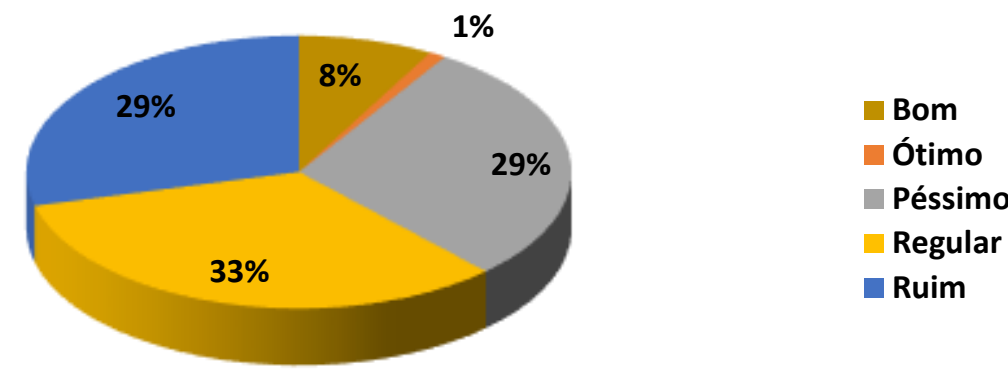

Figura 9. Informações sobre itinerários, rotas e horários dos ônibus.

Fonte: Elaborado pelos autores.

Nesse universo pesquisado percebe-se claramente que falta um maior acesso dos usuários as informações sobre mudanças de rotas e dos horários, visto que muitos reclamaram que ficam sabendo das mudanças em cima da hora, sem poder fazer um planejamento antes (Figura 9). Entretanto a SMTU informa que toda mudança em rotas e itinerários são divulgados em jornais de grande circulação, informados em redes sociais, e colocados cartazes dentro doscoletivos. Apenas 1\% avaliou como ótimo, $8 \%$ como bom, 33\% avaliaram como regular essa identificação e o acesso às informações, sendo que $29 \%$ avaliaram como ruim ou péssimo a forma como são comunicados nas mudanças de rotas e itinerários e a identificação dentro dos veículos. 


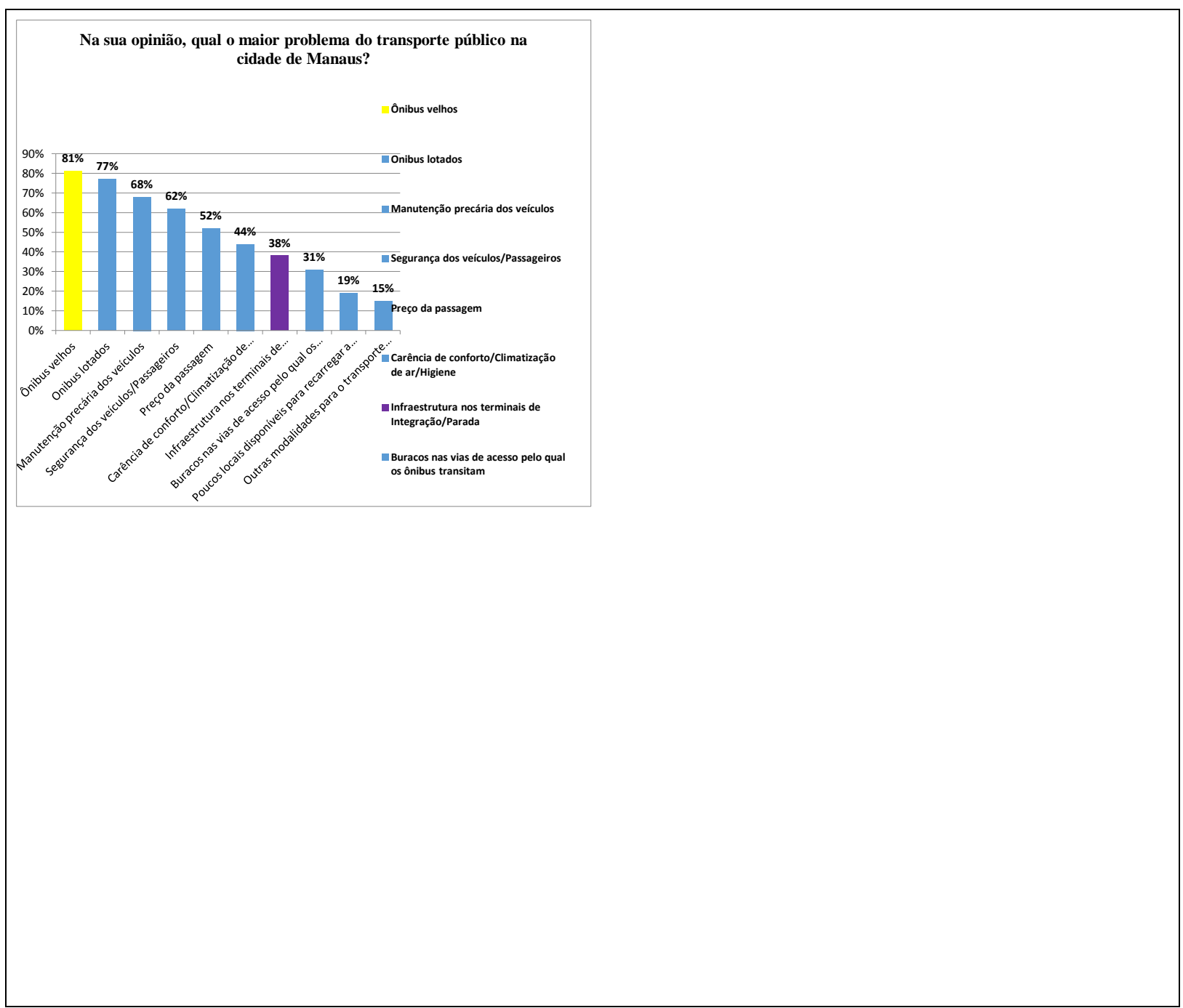

Figura 10. Maior problema do transporte público na cidade de Manaus.

Fonte: Próprios Autores (2019).

A qualidade do serviço é um fator de importância para satisfazer as expectativas dos usuários que o utilizam (Figura 10). Segundos $81 \%$ os usuários do transporte coletivo em Manaus, as condições dos ônibus que rodam pela cidade é o maior problema do serviço oferecido, podendo gerar desconforto na viagem, como a quebra de um ônibus ocasionado a demora em chegar aodestino final. 68\% disseram que um dos problemas é a manutenção precária dos veículos, muitos ônibus estão em situaçãoproblemáticacom janelas quebradas, falta de higiene dentro dos coletivos, portas que não abrem direito, acentos soltos, uma série de condições que só contribuem para a péssima qualidade desse serviço.

O serviço de transporte urbano tem uma demanda alta de usuários, e a quantidade de ônibus não a supri fazendo com que muitos ônibus estejam sempre lotados em seus trajetos. Essa lotação nos ônibus da cidade é considerada o segundo maior problema por $77 \%$ dos usuários. $62 \%$ disseram ser a falta de segurança nos veículos esta relacionado com os acidentes e os assaltos que acontecem durante o trajeto, muitos ônibus não contem segurança pela as condições que se encontra e não contem câmeras de segurança estaladas. $52 \%$ dos usuários mostraram insatisfação com o valor da passagem, pois o serviço oferecido não é de qualidade, muitos revelaram que o preço é injusto. 
A experiência obtida pelos os usuários no serviço è importante para que eles retornem a utilizá-lo. Como verificado, cerca de $44 \%$ apontaram que a falta de conforto, ar-condicionado e a higiene dentro dos veículos são os maiores problemas encontrados atualmente. 38\% afirmaram que a falta de infraestrutura dos terminais de integração e as paradas de ônibus é um dos maiores problemas. $31 \%$ apontaram que os buracos nas vias pelas quais os veículos transitam seja o maior problema encontrado. Satisfazer as expectativas dos usuários é fundamental para que eles voltem a fazer uso desse serviço.

\section{DISCUSSÃO DOS RESULTADOS}

De acordo com os dados obtidos na pesquisa, podemos elencar alguns pontos críticos observados pelos usuários do transporte público na cidade de Manaus, que serão abordados a seguir:

a) Tempo de espera: De acordo com a Prefeitura de Manaus, foi desenvolvido pelo Sinetram o aplicativo "Cadê meu ônibus?", com o objetivo de informar os horários que os itinerários estarão passando pelas paradas de ônibus, e de reduzir o tempo de espera, pois os usuários obtêm as informações dos veículos através dos GPS's instalados nos ônibus, que indicam em tempo real, o horário dechegada à parada no qual o usuário se encontra. Dessa maneira evita que a pessoa passe muito tempo na espera do ônibus nas paradas, evitando maiores transtornos.

b) Ônibus Velhos: Identificado como um dos principais problemas no transporte público da cidade de Manaus, os ônibus velhos que estão circulando pelas ruas de nossa cidade, contribuipara aumentar a insatisfação dos usuários, pois os mesmos reclamam que muitos ônibus quebram pelas ruas antes de finalizarem a viagem, não oferecem o mínimo conforto a população, são sujos, caindo aos pedaços, apresentam muitos barulhosna estrutura do ônibus, portas que não abrem em conformidade, esses são alguns dos relatos da população que todos os dias utilizam o meio de transporte público. A prefeitura informa que existe um planejamento queviabilizaa chegada de novos ônibus para poder trocar a frota, mas tudo depende da logística.

c) Super Lotação: Outros grandes problemas são os ônibus que andam sempre lotados, principalmente nos horários de pico, a população reclama quenesse momento sempre enfrenta esse tipo de problema. A prefeitura diz que realiza estudos para identificar as rotas que precisam de aumento no número de veículos para atender a demanda. Uma das soluções seria o transporte em massa, como metrô, BRT, que funcionaria de forma mais rápida, pois circularia em vias exclusivas e transportaria mais pessoas devido ao fato de serem maiores.

d) Segurança: Dentro dos veículos incomodam a população que cada vez mais se sente insegura dentro do coletivo, devido a constante onda de assaltos que ocorrem dentro dos ônibus. Segundo a prefeitura, parceria com a Polícia militar através de blitz/barreiras, visa coibir a crescente criminalidade dentro dos ônibus. Uma alternativa proposta pelo Sinetram seria o pagamento apenas através da bilhetagem eletrônica, como a passa fácil, essa medida diminuiria a circulação de dinheiro dentro dos coletivos, mas quem protegeria os passageiros? Sem mencionar que os poucos postos de recarga do cartão passam fácil é um dos problemas citados pelas pessoas durante a pesquisa.

e) O preço: O preço da passagem não é considerado justo pelo péssimo serviço oferecido a população, muitos reclamaram que pagam um valor alto frente à qualidade do que é ofertado 
atualmente. A infraestrutura das paradas de ônibus também foi considerada péssima pelaspessoas na aplicação do questionário, muitas locais não tem um abrigo que possam esperar o coletivo com mais comodidade, enfrentando o sol forte e chuva, devido às condições mínimas que uma parada deve oferecer também os terminais de integração foram avaliados como péssimos, com diversos problemas que ainda persistem, falta uma melhor organização nos terminais, sinalização, banheiros quebrados, terminais sem nenhum tipo de segurança, telhados quebrados, não oferecendo uma estrutura adequada para tal função que deveria existir. A prefeitura informa que existe um cronograma com o objetivo de reformar os terminais de integração, e até mesmo desativar alguns, quanto às paradas de ônibus será iniciado a construção de abrigos em lugares que não existem tudo depende da empresa que vencerá a licitação.

f) Falta de manutenção dos veículos: É apontado como um dos problemas do transporte público da cidade de Manaus, alinhado com os buracos nas vias pelas quais os ônibus transitam, fazendo com que cada vez mais os veículos fiquem sem condições de uso, ao terem peças quebradas e consequentemente deixando de circularem pelas vias. A prefeitura informou que diversas ruas foram e serão asfaltadas, e detém um controle das que mais necessitam de reparos, visando diminuir os constantes buracos que ajudam a contribuir com esses índices negativos quanto a qualidade do serviço público do transporte na cidade.

g) Opções de modalidades: Um dos últimos problemas descritos pelos usuários ao responder nossa pesquisa, foi à falta de outra modalidade que possa servir de meio de transporte público, nesse contexto, relatamos sobre um transporte em massa como o metrô, VLT, BRT. Os governantes precisam pensar em uma nova modalidade que possa ser implementada de forma mais rápida e que traga soluções para o serviço de transporte público que hoje é oferecido ao manauara. Precisa pensar em alternativas que possam melhorar o transporte público, não apenas imaginar que uma faixa azul resolverá todo esse problema. Uma parceria com a iniciativa privada faria com que pudesse programar essas novas alternativas, isso contribuiria para uma qualidade desse serviço, e aumentaria a eficiência que atualmente não existe.

\section{CONSIDERAÇÕES FINAIS}

As comodidades do transporte público coletivo são substâncias que resultam tanto na progressão social como a econômica de Manaus ou até mesmo do Brasil, precipuamente, em regiões metropolitanas que requer com diligência o serviço para atender uma vasta demanda de clientes. Todavia, compreende-se que a entidade pública não obtém ofertar um transporte público de excelência e que consiga atender ao seu usuário.

O estudo concluiu que parte dos usuários do transporte público coletivo na cidade de Manaus, que utilizam o mesmo, estáinsatisfeita com as prestações de serviços no tecido social. Observou-se que a insegurança, o preço da passagem, e falta de ônibus para atender a vasta demanda da cidade são fatores proeminentes de disfunções apresentadas pelos os usuários. $\mathrm{O}$ desfecho coletado a partir da pesquisa realizada deixa evidente que o sodalício vem sendo desafiado por problemas de hábito e cultura quanto a acessibilidade e a locomoção para o acesso ao destino final do usuário. Essa problemática influencia diretamente no esgotamento humano devido ao estresse que lhes é causado no dia a dia, destaca-se que a falta de qualidade no transporte público é um apontamento uniforme exposto por parte dos usuários. A insuficiência de um transporte público que atenda a sociedade quanto a sua locomoção e acessibilidade é um ponto fulcral para compreender como grandes metrópoles carecem de inversão em mobilidade urbana. 
Analisaram-se os atributos que influenciam o resultado de satisfação e desempenho dos usuários com a qualidade do transporte coletivo da cidade de Manaus. A partir de uma entrevista com 500 usuários, obteve-se um catálogo de atributos, ilustres em heterogêneas proporções teóricas. Através dos dados qualitativos, foi viável construir a pesquisa (questionário) o qual serviu de instrumento de para mensurar a satisfação com os atributos que geram repercussões na qualidade dos serviços prestados de transporte coletivo. Por conseguinte, os atributos intimatórios e seus respectivos fatores identificados por esta pesquisa são aportes de critério acadêmico e contribui para subsidiar a administração pública na elaboração de projetos e licitações, além de conter informações relevantes aos prestadores dos serviços de transporte coletivo interessados na qualidade e satisfação dos passageiros.

A utilidade do transporte coletivo exerce importância na qualidade de vida do tecido social, principalmente em grandes centros urbanos, onde a mobilidade é primordial para a população. A pesquisa realça o valor da satisfação dos usuários do serviço, bem como suas contribuições que partem da identificação dos problemas e de seus fatores para a satisfação dos usuários, sobretudo na influência da conduta de avaliação de satisfação dos cidadãos que usufruem do serviço de transporte coletivo, sendo capaz de ser considerado como uma referência para futuros estudos em trabalhos semelhantes que envolvam a qualidade no transporte coletivo urbano na cidade ou até mesmo no país, considerando os poucos estudos e ainda incipientes acerca do tema em Manaus. Destacam-se ainda as contribuições práticas para a administração do serviço de transporte coletivo local e da prefeitura de Manaus. Há fatores que resultaram do estudo caracterizam fatores extremamente críticos de êxito para os usuários do transporte coletivo, os quais devem ser monitorados devidamente pelo poder público local e pelas empresas que realizam o respectivo serviço de transporte, visando à satisfação dos usuários e à elevação do número de usuários do referido transporte de modo a reduzir o congestionamento na cidade.

Cabe aos agentes de ônibus aprimorar frequentemente o desempenho da qualidade dos serviços de transporte coletivo, visto que dessa forma se eleva significativamente a satisfação geral dos passageiros. Este estudo auxilia para fornecer utensílios e referências aplicáveis para tornar a era de melhoria um processo contínuo no transporte coletivo urbano em Manaus, servindo inclusive como benchmarking e respaldado por pesquisa pública visando à qualidade de vida e mobilidade da população. Uma das limitações do estudo é a não probabilidade de generalizar os resultados, tendo em vista que a pesquisa se restringiu a uma única cidade Manaus - e a um único meio de transporte coletivo: o ônibus.

Os atributos e fatores identificados pela pesquisa são exclusivamente para atender à solicitação deste estudo, porém se reaplicado por outros pesquisadores, caberá uma comparação tendo como referência os resultados divulgados, os quais contribuem para ampliar o conhecimento do tema. Para pesquisas futuras, recomenda-se reaplicar a metodologia adotada, com amostras de usuários de serviços de transporte coletivo de Manaus ou do Brasil, assim como usuários de serviços prestados de outros meios de transporte. Existe a perspectiva de confrontar as características e os fatores identificados por este estudo com outros trabalhos semelhantes envolvendo o transporte coletivo em regiões diferentes do país. Estudos inerentes à ação sociocultural sobre os atributos e fatores de satisfação regional (Manaus). Por fim, é provável um estudo de fatores motivacionais envolvendo a classe social para amparo do transporte coletivo, portanto, a partir deste artigo, outras pesquisas poderão ser realizadas a fim de ampliar e a compreender a satisfação dos usuários com a qualidade dos serviços de transporte público. 


\section{REFERÊNCIAS}

Agum, R., Riscado, P., \& Menezes, M. (2015). Políticas públicas: conceitos e análise em revisão. Agenda Política, 3(2), 12-42.

Almeida, Cecilia, Franco, Pinheiro,\&Ventura. (2017). Mobilidade urbana e transporte público em Manaus. Recuperado de: https://medium.com/lab-f5/mobilidade-urbana-etransporte-p\%C3\%BAblico-em-manaus-1e562525706c.

Strehl, E. G., Moyano, C. A. M., \&Angnes, D. L. (2019). Atributos Qualitativos e Fatores de Satisfação com o Transporte Público Urbano por Ônibus. Contextus - Revista Contemporânea de Economia e Gestão, 17(1), 98-126.

Araújo, M. R. M., Oliveira, J. M., Jesus, M. S., Sá, N. R., Santos, P. A. C., \& Lima, T. C. (2011). Transporte público coletivo: discutindo acessibilidade, mobilidade e qualidade de vida. Psicologia \& Sociedade, 23(3), 574-582.

Portaluppi, J., Heinzmann, L. M., Tagliapietra, O. M., \& Borilli, S. P. (2006). Análise do atendimento e satisfação dos clientes: Estudo de caso de uma empresa de insumos agrícolas. Revista de Ciências Empresariais da UNIPAR-RECEU, 7(1), 75-91.

Terra, S. X.,\& Duarte, P. C. (2014). Estudo da qualidade no sistema de transporte coletivo urbano por ônibus na cidade de Pelotas, RS. Revista de Engenharia da Faculdade Salesiana, (1), 6-10.

Günther, I. A. (1986). Pesquisa para conhecimento ou pesquisa para decisão? Psicologia: Reflexão e Crítica, 1(1), 75-78.

G1 Amazonas. (2015). Grupo manifesta contra aumento da passagem de ônibus em Manaus. Recuperado de: http://g1.globo.com/am/amazonas/noticia/2015/01/grupo-manifestacontra-aumento-da-passagem-de-onibus-em-manaus.html.

Las Casas, A.L. (2008). Qualidade Total em Serviços. Editora Atlas S.A.

Mota, R. (2019). Transporte coletivo perde 19 milhões de usuários em Manaus. Emtempo, 2019. Recuperado de: https://d.emtempo.com.br/amazonas-cidades/136525/transportecoletivo-perde-19-milhoes-de-usuarios-em-manaus

Rua, M. D. G., \& Romanini, R. (2013). Tipologias e Tipos de Políticas Públicas. Para aprender políticas públicas. Brasília: IGEPP, 48-54.

Souza, B. (2013).Estudantes fazem protesto sobre o aumento da passagem de ônibus na Zona Norte.Recuperado de: https://www.acritica.com/channels/manaus/news/estudantesfazem-protesto-sobre-o-aumento-da-passagem-de-onibus-na-zona-norte. 
Souza, C. (2002). Políticas Públicas: Conceitos, Tipologias e Sub-Áreas. Recuperado de:https://docplayer.com.br/18980674-Politicas-publicas-conceitos-tipologias-e-subareas.html. 